\title{
PRODUTIVIDADE E RENDIMENTO DO CAFEEIRO NAS CINCO PRIMEIRAS SAFRAS IRRIGADO POR PIVÔ CENTRAL EM LAVRAS, MG ${ }^{1}$
}

\author{
Coffee yield and production during the initial five harvests under irrigation with \\ center pivot in Lavras, MG
}

\author{
Luiz Antônio Lima², Anselmo Augusto de Paiva Custódioº ${ }^{3}$ Natalino Martins Gomes ${ }^{4}$
}

\begin{abstract}
RESUMO
Com a racionalização da exploração agrícola a caminho da sustentabilidade e a incorporação de novas tecnologias pela cafeicultura, tornam-se necessários o domínio, o conhecimento e o manejo dos principais fatores relacionados à produção, dentre os quais a irrigação é de fundamental importância. Avaliou-se o efeito da irrigação na produtividade e no rendimento do café da roça em lavoura irrigada por pivô central na região de Lavras, MG. O experimento foi conduzido em lavoura cafeeira da cultivar Rubi MG1192, plantada em março de 1999, com espaçamento de 3,5 m entre linhas e $0,8 \mathrm{~m}$ entre plantas. O delineamento experimental adotado foi o de blocos casualizados, com seis tratamentos e três repetições. As irrigações foram realizadas em turnos de rega fixos de 2 e 3 dias (segundas, quartas e sextas-feiras), com base no balanço entre a evaporação do tanque classe A (ECA) e as precipitações, aplicandose à diferença os porcentuais $0 \%$ ECA (T1, não irrigado), 60\% ECA (T2), 80\% ECA (T3), 100\% ECA (T4), 120\% ECA (T5) e 140\% ECA (T6). Após a derriça e homogeneização do café colhido nas parcelas experimentais, amostras de café da roça foram acondicionadas em sacaria de fio de plástico trançado e submetidas à secagem em bancadas de madeira suspensa ao ar livre, até atingirem umidade entre 11 e $12 \%$ com base em peso. Após a secagem, procedeu-se o beneficiamento (retirada da casca) e pesagem das amostras para estimativa da produtividade e do rendimento. A irrigação promoveu acréscimo na produtividade dos tratamentos irrigados quando comparada à produtividade da testemunha; mesmo não havendo diferença estatística significativa na comparação de safras anuais para as irrigações nota-se, ao comparar a produção total acumulada das safras, diferença estatística entre a testemunha e os tratamentos irrigados. Dentre os tratamentos analisados destacou-se a lâmina de 60\% da ECA, com a qual a produção total acumulada foi de 225,6 sc e a média anual de $45,12 \mathrm{sc} \mathrm{ha}^{-1}$, com acréscimo de $119 \%$ na produtividade do cafeeiro quando comparada ao tratamento não irrigado, que produziu, em média, $24 \mathrm{sc} \mathrm{ha}^{-1} \mathrm{ano}^{-1}$. O grau de maturação, no momento da colheita, influenciou o rendimento dos tratamentos, sendo os frutos nos estádios cereja e seco, os que mais interferiram no rendimento.
\end{abstract}

Termos para indexação: Cafeicultura, irrigação, produtividade e rendimento.

\begin{abstract}
Search for sustainability on agricultural exploration and incorporation of new technologies impose the necessity for knowledge and management of main factors related to production, such as irrigation. This experiment evaluated the irrigation effect on yield and production efficiency (amount of beans to produce a bag of $60 \mathrm{Kg}$ ) of coffee irrigated by center pivot in LavrasMG, Brazil. The experiment was planted with the cultivar Rubi MG-1192, planted on March, 1999. spaced 3.5 meters between rows and 0.8 meters between plants. The experimental design was the one of randomized blocks, with six treatment levels and three replicates. The irrigation was applied at intervals of 2 or 3 days, on Mondays, Wednesdays and Fridays, based on the amount estimated by the water blance considering the class A pan evaporation (ECA) and rain depths. The irrigation was calculated as $0 \%$ of the difference between ECA and rain depth - 0\% ECA (T1, non irrigated), 60\% ECA (T2), 80\% ECA (T3), $100 \%$ ECA (T4), 120\% ECA (T5) and 140\% ECA (T6). After harvesting the coffee grains from the experimental plots, coffee samples were packed in ventilated plastic bags and dried on wood benches exposed to air long enough to decrease its moisture content between 11 and 12\%, gravimetric water content. After drying, the beans were unpeeled and weighed to calculate the yield and production efficiency. Irrigation increased the yield of irrigated plots compared to non irrigated. Although non significant difference was statistically observed when comparing annual yields, the differences were statistically significant when the total production was compared among treatment levels. Application of $60 \%$ ECA resulted in a total production along five years of 225.6 bags, with annual average of 45.12 bags per hectare, representing an increase of $119 \%$ when compared to the non irrigated treatment, where the annual average was 24 bags per hectare. The beans were ripened differently among treatments and this fact influenced the production efficiency, being the dry and ripen fruits, those mostly affected.
\end{abstract}

Index terms: Coffee production, coffee yield, irrigation.

(Recebido em 9 de março de 2006 e aprovado em 31 de maio de 2008)

\footnotetext{
'Projeto financiado pelo PNP\&D/CAFÉ - EMBRAPA (19.2002.317-05);

2Engenheiro Agrícola, Ph.D., Professor - Departamento de Engenharia/DEG - Universidade Federal de Lavras/UFLA - Cx. P. 3037 - $37200-000$ Lavras, MG - lalima@ufla.br

${ }^{3}$ Engenheiro Agrônomo, Mestrando em Engenharia de Água e Solo - Departamento de Engenharia/DEG - Universidade Federal de Lavras/UFLA - Cx. P. 3037 - 37200-000 - Lavras, MG - b1uflagro@yahoo.com.br

${ }^{4}$ Engenheiro Agrícola, Doutor em Engenharia de Água e Solo, Professor Escola Agrotécnica Federal Antônio José Teixeira/EAFAJT - Distrito de Ceraíma, Zona Rural - Cx. P. 09 - 46430-000 - Guanambi, BA - natalagricola@yahoo.com.br
} 


\section{INTRODUÇÃO}

A cafeicultura é uma das principais atividades agrícolas da região Sul do estado de Minas Gerais, ocupando lugar de destaque em função da geração de divisas e empregos que tem proporcionado à região, ao longo dos anos. Estima-se que mais de 50\% do café produzido em Minas Gerais, 21,14 milhões de sacas na safra 06/07, tenha sido colhido na região sul e oeste de Minas Gerais (AGRIANUAL, 2007).

Considerada como apta ao cultivo do café, por apresentar precipitação média anual superior a $1500 \mathrm{~mm}$ (BRASIL, 1992), até o início dos anos 90, não era comum, nessa região, a realização de pesquisas relacionando os efeitos da irrigação com o desenvolvimento vegetativo, sanidade, produtividade e rendimento das lavouras cafeeiras. Mas, resultados obtidos por pesquisadores após a implementação do Programa Nacional de Pesquisa e Desenvolvimento da Cafeicultura (PNP\&D/Café) têm justificado a adoção dessa técnica em função dos incrementos proporcionados à produção (SILVA et al., 2002).

A partir de meados dos anos 90 , a irrigação foi fortemente implantada em lavouras cafeeiras, pois os aumentos de produtividades quando da sua utilização tornaram-se atrativos e justificavam o investimento.

Silva et al. (2003) avaliaram o efeito de duas épocas de irrigação para a cultura do café na região de Lavras durante a safra 1999/2000: junho a outubro e setembro a outubro, comparando-as às plantas não irrigadas. Embora os tratamentos não apresentassem diferenças entre os rendimentos $\left(\mathrm{L} \mathrm{sc}^{-1} 60 \mathrm{~kg}\right)$, colheram 97,74; 18,38 e 7,21 sc ha $^{-1}$ de café beneficiado, respectivamente, concluindo que as plantas irrigadas no período de junho a outubro apresentaram maiores produtividades que as demais.

Trabalhando com lavoura cafeeira não irrigada, irrigadas com aspersão em malha e pivô central equipado com LEPA (low energy precision application), na Zona da Mata Mineira, Contin et al. (2005) avaliaram a produtividade de cafeeiros da variedade Topázio com trinta e seis meses de idade, safra 2003/2004, e registraram as produtividades de 14,7; 21 e $29 \mathrm{sc} \mathrm{ha}^{-1}$, o que mostra a influência positiva da irrigação na produtividade do cafeeiro, nos diferentes sistemas avaliados.

Saber o quanto vai colher é sempre uma informação desejada por parte dos produtores e quando se fala em cafeicultura, é comum o produtor estimar a safra em função do rendimento da lavoura, ou seja, quantidade de café da roça, necessária para fazer uma saca de $60 \mathrm{~kg}\left(\mathrm{~L} \mathrm{sc}^{-1}\right)$. Clemente et al. (2002) estudaram o efeito da época de irrigação na produtividade e no rendimento do café da roça e concluíram que as plantas irrigadas entre set./nov. apresentaram produtividade acima de $60 \mathrm{sc} \mathrm{ha}^{-1}$, sendo essa superior às demais. Com relação ao rendimento, relatam que as plantas irrigadas entre os meses de abril/ jun. apresentaram o pior rendimento $\left(540 \mathrm{~L} \mathrm{sc}^{-1}\right)$, já as irrigadas entre ago./out. apresentaram o melhor rendimento $\left(465 \mathrm{~L} \mathrm{sc}^{-1}\right)$. Atribuíram esse fato ao somatório dos maiores porcentuais de frutos nos estádios seco e passa $(52,54 \%)$, no momento da colheita. Melo et al. (2005) irrigaram plantas da cultivar acaiá cerrado, com lâmina de $120 \%$ da ECA por gotejamento e conseguiram rendimento de $437 \mathrm{~L} \mathrm{sc}^{-1}$ e produtividade média de $48,51 \mathrm{sc} \mathrm{ha}^{-1}$, na região de Uberlândia, MG, para a safra de 2004. Rezende et al. (2006), avaliando lâminas de irrigação em lavoura cafeeira recepada, cultivar Topázio MG-1190 aos 65 meses após plantio, verificaram que, com a prática da irrigação, houve aumentos de produtividade do cafeeiro, contribuindo para melhorar o rendimento da lavoura e retardando a maturação dos frutos.

Coelho (2005), trabalhando com épocas de irrigação, parcelamentos de adubação e custo de produção do cafeeiro 'Catuaí', na região de Lavras - MG, concluiu que a irrigação somada à fertirrigação representa de $5 \%$ a $12 \%$ do custo de produção da atividade cafeeira. Por outro lado, a irrigação entre 01/06 e 30/09 seja fertirrigada ou com aplicação manual de adubos, proporcionaram aumentos significativos de produtividade, além de eliminar o ciclo bienal de produtividade do cafeeiro.

Gomes et al. (2007), avaliando o efeito da irrigação na produtividade em lavoura cafeeira irrigada nas cinco primeiras safras, plantada em março de 1999 no espaçamento de 3,5 m x 0,8m, cultivar Rubi MG-1192 na região de Lavras, concluíram que a irrigação promoveu aumento satisfatório na produtividade dos tratamentos irrigados quando comparada à testemunha, sendo a lâmina de $60 \%$ ECA, a que apresentou produtividade média de $45,12 \mathrm{sc}$. ha- ${ }^{-1} \mathrm{ano}^{-1}$, superior às demais e estatisticamente superior à testemunha $(24,0 \mathrm{sc}$. ha${ }^{1}$ ano $^{-1}$ ), apresentando também os melhores resultados de crescimento vegetativo.

Já Silva et al. (2005), avaliando os efeitos da irrigação na cultura do café na produção acumulada das seis primeiras colheitas em Lavras, cultivar acaiá cerrado MG-1474, no espaçamento de 3,0 m x 0,6 m e irrigadas por gotejamento na área efetivamente irrigada concluíram que a irrigação do cafeeiro produziu efeitos significativos sobre a produtividade acumulada sendo melhor o tratamento testado a lâmina de $100 \%$ da ECA, a qual proporcionou maior rendimento e produção (51\% superior ao tratamento testemunha). 
Nota-se entre os estudos citados, variações nas produtividades obtidas com a irrigação, e os produtores da região sul de Minas Gerais dispõem de diferentes formas de ensaios com resultados de pesquisas, sobre os benefícios da irrigação na cafeicultura. Com a criação do Programa Nacional de Pesquisa e Desenvolvimento da Cafeicultura (PNP\&D/Café), pesquisas com irrigação foram intensificadas, visando apoiar o suporte técnico para que haja uma tecnologia fundamentada e propulsora de lucratividade e sustentabilidade aos cafeicultores. Neste contexto, objetivou-se com este trabalho estudar o efeito de diferentes lâminas de irrigação sobre a produtividade e rendimento do café da roça, para a cultivar Rubi MG-1192, nas cinco primeiras safras, em Lavras, Sul de MG.

\section{MATERIAL E MÉTODOS}

Plantas da cultivar Rubi MG-1192 foram instaladas em março de 1999, em nível, no espaçamento de 3,5 m entre linhas e $0,8 \mathrm{~m}$ entre plantas, com densidade de plantas de 3.571 plantas ha $^{-1}$, em área experimental do Departamento de Engenharia da Universidade Federal de Lavras - UFLA, MG, com $14 \%$ de declive e norte verdadeiro (Figura 1) em latitude de $21^{\circ} 13^{\prime} 42,73^{\prime \prime}$ South, longitude de 445' $37,72^{\prime \prime}$ West e altitude de $918 \mathrm{~m}$. O solo da área foi classificado como Latossolo Vermelho escuro, tendo as seguintes características químicas: pH em água, 4,6; matéria orgânica,
1,9 dag $\mathrm{kg}^{-1}$; P disponível (Mehlich-1), 5,2 $\mathrm{mg} \mathrm{dm}^{-3}$; potássio, magnésio, alumínio tocáveis de 0,$3 ; 0,9$ e $0,4 \mathrm{cmol}_{\mathrm{c}}$ $\mathrm{dm}^{-3}$, respectivamente; $\mathrm{H}+\mathrm{AL}, 6,3 \mathrm{cmol}_{\mathrm{c}} \mathrm{dm}^{-3}$; CTC a pH 7,0 de $8,6 \mathrm{cmol}_{\text {c dm}} \mathrm{dm}^{-3}$ e saturação de base de $26,3 \%$. A composição textural do solo, na área experimental, é muito argilosa, apresentando $22 \%$ de areia, $2 \%$ de silte e $76 \%$ de argila. Considerando-se a primeira camada de 0 a $25 \mathrm{~cm}$, o solo possui umidade à capacidade de campo de $48 \%$, umidade no ponto de murcha permanente de $42 \%$, densidade aparente média igual a $1,29 \mathrm{~g} . \mathrm{cm}^{-3}$ e densidade de partículas de 2,67 g.cm ${ }^{-3}$.

A região de Lavras, $M G$ possui temperatura média anual normal de $19,4^{\circ} \mathrm{C}$, precipitação média anual de 1529,7 mm e umidade relativa média de 76,2\% (BRASIL, 1992). De acordo com a classificação climática de Köppen, a região possui um clima do tipo $\mathrm{Cwa}$, caracterizado por ser subtropical com inverno seco e chuvas predominantes de verão.

A estação chuvosa na região se estende no período de outubro a março, já a estação seca ocorre no período de abril a setembro (CASTRO NETO \& VILELA, 1986).

$\mathrm{O}$ delineamento experimental adotado foi o de blocos casualizados, com 6 tratamentos e 3 repetições, correspondendo às lâminas de água aplicadas em função da evaporação do tanque classe A (ECA), assim descritos: $60 \%$ (T2), $80 \%$ (T3), 100\% (T4), 120\% (T5) e $140 \%$ (T6) da ECA, e tratamento testemunha (T1), não irrigado. A área

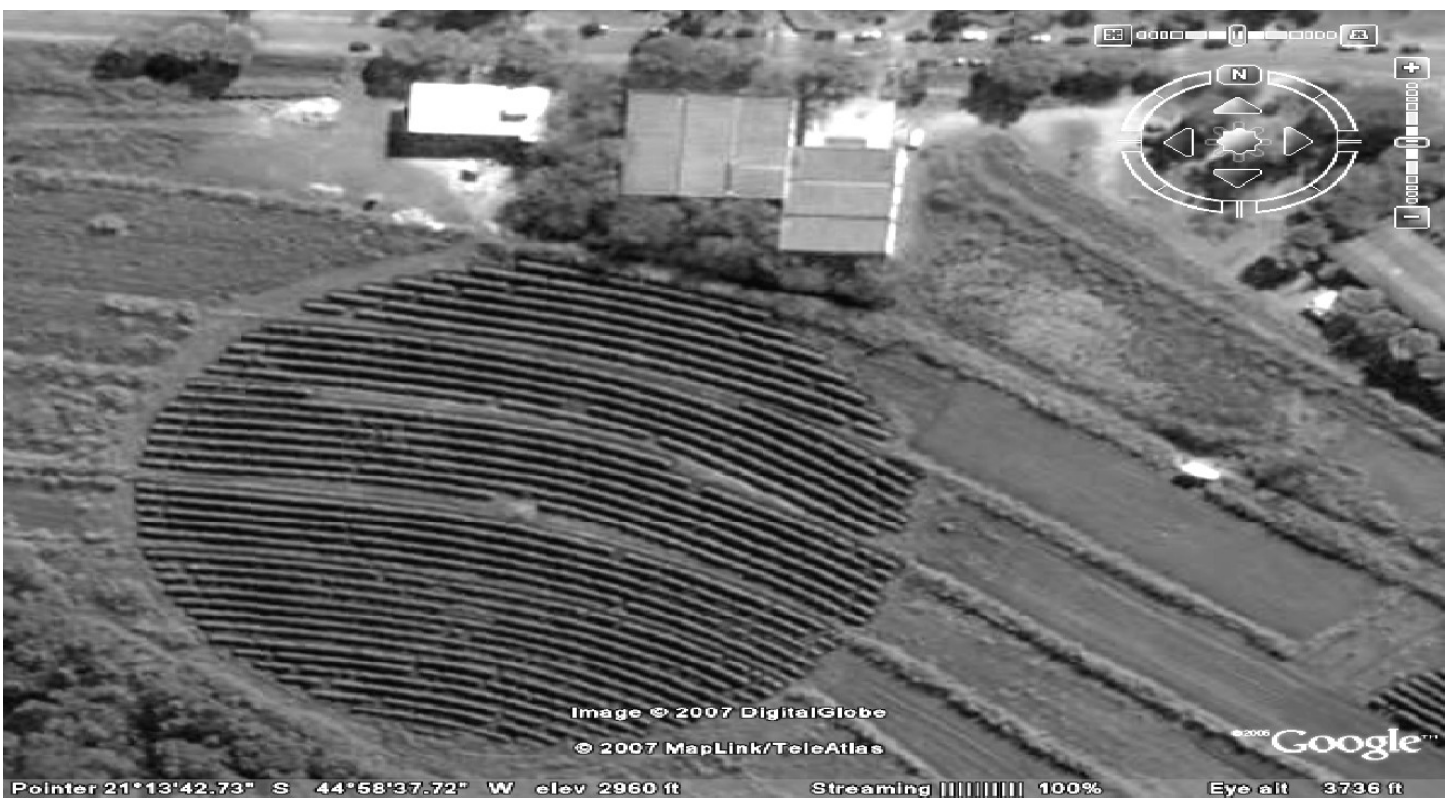

Figura 1 - Vista do campo experimental com orientação norte verdadeiro. UFLA - Lavras, MG, 2007. Fotografia retirada

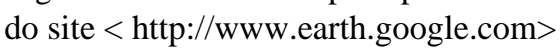


irrigada corresponde a 1,6 ha no sistema de irrigação por aspersão, tipo pivô central equipado com difusores (spray) distanciados aproximadamente 2,20 m entre si e 2,0 m acima das copas das plantas. A área foi dividida em subáreas ( segmentos de $20^{\circ}$ ), que constituíram as parcelas experimentais. Dentro dessas parcelas foram amostradas oito plantas para avaliação da produtividade e rendimento do café da roça.

O monitoramento da ECA, base para os cálculos das lâminas a serem aplicadas, bem como os dados de precipitação, temperatura média e umidade relativa foram coletados diariamente na Estação Climatológica, pertencente ao $5^{\circ}$ Distrito de Meteorologia do Instituto Nacional de Meteorologia (INMET) em convênio com a UFLA, situada a aproximadamente 380 metros do experimento. Adotaram-se turnos de regas fixos de 2 e 3 dias (segundas, quartas e sextas-feiras), para a realização das irrigações. Nos dias em que ocorreram precipitações, foram feitos balanços entre o total precipitado e a evaporação no período, se a ECA > P irrigava-se, se ECA $=\mathrm{P}$ não havia necessidade de irrigar.

As diferentes lâminas d'água correspondentes aos tratamentos foram controladas mediante o ajuste da velocidade do pivô (regulagem do porcentímetro), sendo o pivô avaliado nos anos de 1999 e 2004 com coeficiente de uniformidade de christiansen (CUC), respectivos de $83 \%$ e $88 \%$, sendo esses coeficientes enquadrados, conforme Bernardo et al. (2006), como de uniformidade ótima. No tratamento testemunha, o pivô central deslocava-se sobre as parcelas, sem aplicar lâmina d'água. Os tratos culturais foram feitos de maneira convencional, sendo as adubações de acordo com Santinato et al. (1996).

A colheita das parcelas foi feita de forma manual sobre "pano". Após a derriça e homogeneização do café colhido, tomaram-se amostras de $10 \mathrm{~L}$ de café da roça para estimar a produtividade bem como o rendimento das parcelas experimentais. Dessas retiraram-se subamostras de $1 \mathrm{~L}$ para avaliar o grau de maturação, ou seja, contagem dos grãos nos estádios verde, verde-cana, cereja, passa e seco. Após esse procedimento, essas subamostras voltavam a compor novamente as amostras maiores, sendo essas acondicionadas em sacarias de fio plástico trançado e submetidas à secagem em bancadas de madeira suspensas ao ar livre até atingirem umidade na faixa de 11 a $12 \%$ com base em peso, quando então procedeu-se ao beneficiamento (retirada da casca) e pesagem. Após os cálculos, os valores encontrados foram submetidos à análise de variância e teste de comparação de média, ao nível de 5\% de probabilidade pelo programa SISVAR. As variáveis estudadas referem-se às safras 2000/2001, 2001/ 2002, 2002/2003, 2003/2004 e 2004/2005.

\section{RESULTADOS E DISCUSSÃO}

\section{Precipitações e lâminas aplicadas}

Os valores médios de precipitação $(\mathrm{P})$ e evaporação do tanque classe A (ECA) para Lavras, no período em que o experimento foi realizado (1999 a 2005) encontram-se na Figura 2. Para o período houve concentração das precipitações para a região de Lavras, entre os meses de novembro a março em que os valores precipitados superam aos da ECA, enquanto nos meses de abril a outubro a precipitação é inferior à ECA, caracterizando-se déficit hídrico no período, conforme citado por Castro Neto \& Vilela (1986).

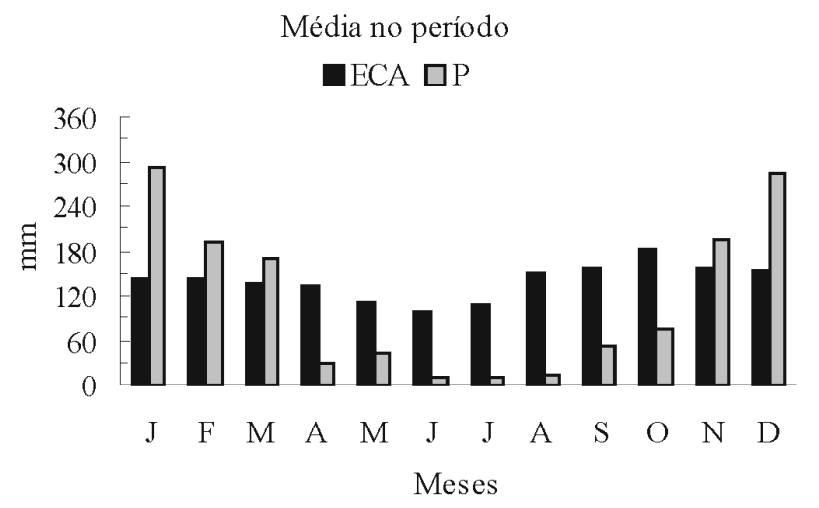

Figura 2 - Totais mensais (mm) para evaporação do tanque classe A (ECA) e precipitação $(\mathrm{P})$. Média para o período de 1999 a 2005. Dados fornecidos pela Estação Climatológica pertencente ao $5^{\circ}$ Distrito de Meteorologia do INMET em convênio com a UFLA - Lavras, MG.

Segundo Santinato et al. (1996), um déficit hídrico de $150 \mathrm{~mm}$ é capaz de comprometer a produção do cafeeiro. Para o período em estudo (set./1999 a set./2005), em dois anos (1999 e 2004), o déficit hídrico ficou abaixo dos 150 $\mathrm{mm}$ em que justifica-se, portanto, a irrigação do cafeeiro, para a região de Lavras, mesmo apresentando precipitação média anual na ordem de 1529,7 mm (BRASIL, 1992). As lâminas aplicadas aos diferentes tratamentos durante o período em que o estudo foi desenvolvido, observam-se na Figura 3. A lâmina do tratamento T1 (0\% ECA) corresponde apenas aos valores precipitados (P). Para os demais tratamentos, somam-se os valores precipitados aos valores da ECA corrigidos pelos fatores 0,6 (T2); 0,8 (T3); 1,0 (T4); 1,2 (T5) e 1,4 (T6). Em termos médios mensais, o tratamento T1 recebeu, ao longo dos 73 meses de avaliações (set./1999 a set./2005), uma precipitação de 113,8 mm; no 
mesmo período, a ECA média foi de $142,9 \mathrm{~mm}$, caracterizando um déficit mensal de 29,1 mm, anual de 394,6 $\mathrm{mm} \mathrm{e}$, ao final do experimento, de $2126,5 \mathrm{~mm}$.

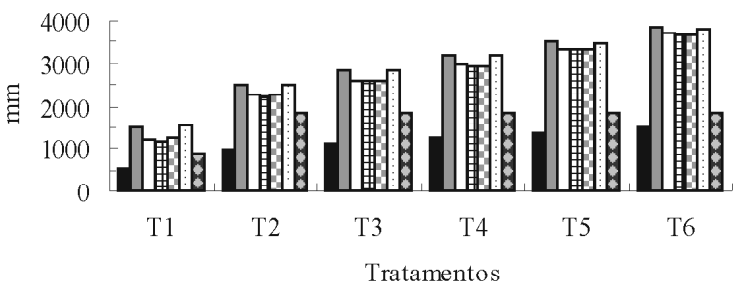

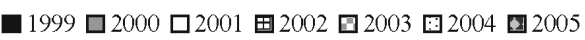

Figura 3 - Lâminas anuais aplicadas aos diferentes tratamentos, acrescidas das precipitações anuais para a região de Lavras, MG, no período de ago./99 a set./05. Os valores de precipitações anuais foram fornecidos pela Estação Climatológica pertencente ao $5^{\circ}$ Distrito de Meteorologia do INMET em convênio com a UFLA - Lavras, MG.

Quando da mesma análise para o tratamento de menor lâmina em estudo T2 (60\% ECA), constata-se que foi aplicada uma lâmina mensal de $209,1 \mathrm{~mm}$, superior em 66,2 mm à ECA média mensal ultrapassando, portanto, o total evapotranspirado em 794,0 $\mathrm{mm}$ no decorrer de um ano, o que equivale à proporção de $0,52 \%$ das precipitações anuais para Lavras. A mesma comparação para os demais tratamentos (T3, T4, T5 e T6), permite constatar que as lâminas médias mensais aplicadas superaram a ECA mensal em 96,0; 125,9; 155,7 e 188,6 mm, respectivamente; anualmente, esses valores chegam a 1152,$2 ; 1510,56$; 1868,8 e $2227,1 \mathrm{~mm}$, o que corresponde a 0,$75 ; 0,98 ; 1,22$ e $1,46 \%$ da precipitação média anual para a região de Lavras, MG.

\section{Produtividade e produção acumulada}

O resumo da análise de variância com a soma de quadrados (SQ), para as produtividades anuais, em sc de $60 \mathrm{~kg} \mathrm{ha}^{-1}$, obtida pela lavoura nas cinco safras para as diferentes lâminas de irrigação, produção acumulada (sc) e produção média ( $\mathrm{sc} \mathrm{ha-1}$ ) encontra-se na Tabela 1 . As produtividades anuais ( $\mathrm{sc} \mathrm{ha} \mathrm{h}^{-1}$ ) para as cinco safras, a

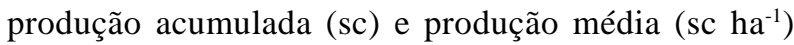
encontram-se na Tabela 2.

Pode-se perceber que não houve diferença estatística para esses parâmetros quando comparadas às produtividades a cada ano, o que não quer dizer que a

Tabela 1 - Resumo da análise de variância com a soma de quadrados (SQ), para a produtividade (café de pano) do cafeeiro cv. Rubi MG-1192 nas safras 00/01, 01/02, 02/03, 03/04, 04/05, produção acumulada (P. Ac.) e produção média (P. M.), em sacas de $60 \mathrm{~kg}$ para as lâminas aplicadas em função do porcentual da ECA. UFLA - Lavras, MG.

\begin{tabular}{lcccccccc}
\hline \multirow{2}{*}{ F.V. } & G.L. & \multicolumn{7}{c}{ Soma de Quadrados } \\
\cline { 3 - 9 } & & $00 / 01$ & $01 / 02$ & $02 / 03$ & $03 / 04$ & $04 / 05$ & P. Ac. & P. M. \\
\cline { 3 - 9 } Lâmina & 5 & $1930,8^{\text {ns }}$ & $3101,4^{\text {ns }}$ & $3723,9^{\text {ns }}$ & $1472,6^{\text {ns }}$ & $314,75^{\text {ns }}$ & $20942,3^{*}$ & $837,6^{*}$ \\
Bloco & 2 & $870,8^{\text {ns }}$ & $2,1^{\text {ns }}$ & $244,6^{\text {ns }}$ & $307,7^{\text {ns }}$ & $33,45^{\text {ns }}$ & $3389,4^{\text {ns }}$ & $135,6^{\text {ns }}$ \\
Erro & 10 & 2554,3 & 2364,7 & 2700,1 & 5796,5 & 1387,6 & 12819,9 & 512,7 \\
Total & 17 & 5356,0 & 5468,3 & 66668,7 & 7576,8 & 1735,8 & 37151,6 & 1485,9 \\
\multicolumn{2}{c}{ C.V. $(\%)$} & 40,11 & 52,29 & 33,09 & 62,52 & 45,14 & 19,51 & 19,51 \\
\hline
\end{tabular}

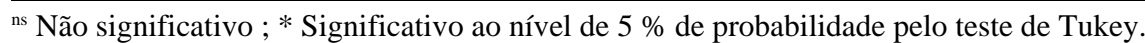

Tabela 2 - Produtividade média (P. M.) e produção acumulada (P. Ac.) em sacas de 60 kg do cafeeiro cv. Rubi MG-1192 para as lâminas aplicadas em função do porcentual da ECA. UFLA - Lavras, MG.

\begin{tabular}{cccccccc}
\hline Lâmina & $00 / 01$ & $01 / 02$ & $02 / 03$ & $03 / 04$ & $04 / 05$ & P. Ac. & P. M. \\
\hline 0 & $18,73 \mathrm{a}$ & $2,95 \mathrm{a}$ & $22,73 \mathrm{a}$ & $50,94 \mathrm{a}$ & $24,53 \mathrm{a}$ & $119,89 \mathrm{a}$ & $23,98 \mathrm{a}$ \\
60 & $49,32 \mathrm{a}$ & $42,82 \mathrm{a}$ & $55,8 \mathrm{ab}$ & $47,97 \mathrm{a}$ & $29,68 \mathrm{a}$ & $225,61 \mathrm{~b}$ & $45,12 \mathrm{~b}$ \\
80 & $38,43 \mathrm{a}$ & $24,37 \mathrm{a}$ & $48,45 \mathrm{ab}$ & $25,26 \mathrm{a}$ & $27,80 \mathrm{a}$ & $164,35 \mathrm{ab}$ & $32,87 \mathrm{ab}$ \\
100 & $44,25 \mathrm{a}$ & $36,20 \mathrm{a}$ & $45,59 \mathrm{ab}$ & $40,92 \mathrm{a}$ & $19,99 \mathrm{a}$ & $186,97 \mathrm{ab}$ & $37,39 \mathrm{ab}$ \\
120 & $39,21 \mathrm{a}$ & $31,93 \mathrm{a}$ & $70,46 \mathrm{~b}$ & $31,54 \mathrm{a}$ & $22,46 \mathrm{a}$ & $195,61 \mathrm{ab}$ & $39,12 \mathrm{ab}$ \\
140 & $49,12 \mathrm{a}$ & $38,13 \mathrm{a}$ & $54,94 \mathrm{ab}$ & $34,39 \mathrm{a}$ & $32,11 \mathrm{a}$ & $208,71 \mathrm{ab}$ & $41,47 \mathrm{ab}$
\end{tabular}

Médias seguidas pela mesma letra, nas colunas, não se diferem estatisticamente entre si pelo teste de Tukey (5\%) 
irrigação não tenha influenciado na produtividade dos tratamentos, exceção feita aos tratamentos irrigados da safra 02/03. Após comparar-se a produtividade média e também a produção acumulada para todas as safras, indicadas na Tabela 1, percebeu-se pelo teste de Tukey (5\%), diferença significativa entre a produção média da testemunha e a produção média acumulada, obtida pelo tratamento com lâmina de água de $60 \%$ da ECA.

Para a quarta safra (03/04), a produtividade do tratamento testemunha alcançou os valores dos tratamentos irrigados devido, provavelmente, à redução da produtividade em função da bienalidade para os tratamentos irrigados e, também, a um possível esgotamento fisiológico dessas plantas que obtiveram produtividades elevadas desde a primeira safra, quando ainda estavam em formação. Comparada aos demais anos, a menor intensidade de déficit hídrico, pode ter contribuído para a elevada produtividade das plantas não irrigadas na quarta safra, igualando esse tratamento aos irrigados.

Observando-se a Figura 4, para o tratamento T1 constata-se que a produtividade da primeira e terceira safra aproximam-se de $20 \mathrm{sc} \mathrm{ha}^{-1}$ ano $^{-1}$, e quase zero para a segunda safra; esse comportamento evidencia a bienalidade da lavoura e mostra que a irrigação pode não evitá-la, mas ajuda a reduzi-la, pois a queda de produtividade nos tratamentos irrigados não foi tão acentuada quanto na testemunha.

É interessante observar que, para avaliar os efeitos da irrigação torna-se necessário acumular as produções, pois a bienalidade da produção impede que comparações de safras, isoladamente, reflitam bem os benefícios da irrigação. Por exemplo, na safra 03/04, a testemunha (sem irrigação) apresentou alta produtividade, sem diferença significativa para os demais tratamentos. Essa variação das produtividades demonstra que experimentos com o cafeeiro demandam, para análise dos efeitos da irrigação

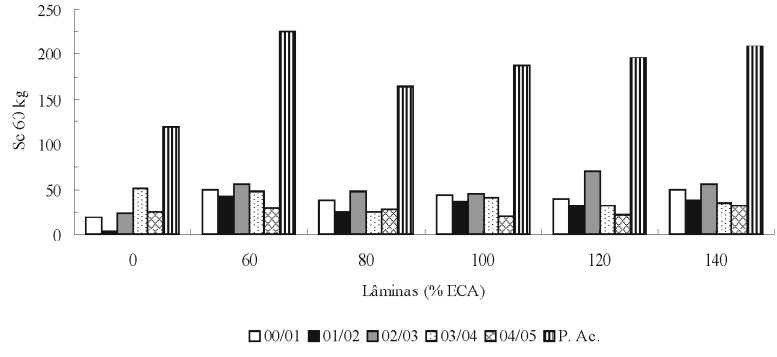

Figura 4 - Produção em sc $60 \mathrm{~kg} \mathrm{ha}^{-1}$ e produção acumulada para as safras estudadas do cafeeiro cv. Rubi MG-1192 em função da lâmina de irrigação aplicada. UFLA - Lavras, MG.

de, no mínimo cinco anos, para comparações entre tratamentos como citado por Custódio et al. (2007).

Observando-se as safras acumuladas (Figura 4 e Tabela 2), o tratamento T2 é o que soma a maior produção acumulada entre todos os tratamentos irrigados ao final de cinco safras, 225,61 sc e produtividade média de 45,12 sc ha ${ }^{-1}$ ano $^{-1}$, seguido do T6, com 208,71 sc ha ${ }^{-1}$ ano $^{-1}$ e produtividade média de $41,47 \mathrm{sc} \mathrm{ha}^{-1} \mathrm{ano}^{-1}$. O T1 teve a menor produção acumulada dentre os tratamentos avaliados, estando próxima de $120 \mathrm{sc}$ ao longo do período analisado e, em média, $24 \mathrm{sc} \mathrm{ha}^{-1} \mathrm{ano}^{-1}$.

\section{Rendimento e Maturação}

O resumo da análise de variância com a soma de quadrados (SQ) e o resultado do teste de médias para o rendimento ( $\mathrm{L} \mathrm{sc}^{-1} 60 \mathrm{~kg}$ ), obtido para todas as safras e lâminas estudadas, está contido na Tabela 3 e 4, respectivamente.

Verifica-se, pelos resultados do teste de médias (Tabela 4), que na primeira safra (00/01) e terceira (02/03) foi registrada diferença significativa para rendimento, com o tratamento não irrigado (T1) diferenciando-se dos demais,

Tabela 3 - Resumo da análise de variância com a soma de quadrados (SQ) para o rendimento ( $\mathrm{L} \mathrm{sc}^{-1} 60 \mathrm{~kg}$ ) do cafeeiro cv. Rubi MG-1192 nas safras 00/01, 01/02, 02/03, 03/04 e 04/05 para as lâminas aplicadas em função da ECA. UFLA Lavras, MG.

\begin{tabular}{|c|c|c|c|c|c|c|}
\hline \multirow[t]{2}{*}{ F.V. } & \multirow{2}{*}{ G.L. } & \multicolumn{5}{|c|}{ Soma de Quadrados } \\
\hline & & $00 / 01$ & $01 / 02$ & $02 / 03$ & $03 / 04$ & $04 / 05$ \\
\hline Lâmina & 5 & $60480,1^{*}$ & $5912,6^{\mathrm{ns}}$ & $17864,8^{*}$ & $7661,4^{\mathrm{ns}}$ & $37781,9^{\mathrm{ns}}$ \\
\hline Bloco & 2 & $4783,5^{\mathrm{ns}}$ & $7360,9^{*}$ & $1342,6^{\mathrm{ns}}$ & $6802,8^{\mathrm{ns}}$ & $198,5^{\mathrm{ns}}$ \\
\hline Erro & 10 & 13299,1 & 8329,3 & 8521,7 & 21824,0 & 27265,4 \\
\hline Total & 17 & 78562,6 & 21602,7 & 27729,2 & 36288,3 & 65245,8 \\
\hline \multicolumn{2}{|c|}{ C.V. $(\%)$} & 7,80 & 6,18 & 6,33 & 9,01 & 13,95 \\
\hline
\end{tabular}

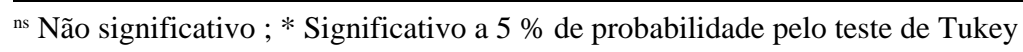


LIMA, L. A. et al.

Tabela 4 - Resultado do teste de médias para o rendimento ( $\mathrm{L} \mathrm{sc}^{-1} 60 \mathrm{~kg}$ ) do cafeeiro cv. Rubi MG-1192 obtido pelas diferentes lâminas de irrigação aplicadas para as cinco safras estudadas. UFLA - Lavras, MG.

\begin{tabular}{|c|c|c|c|c|c|}
\hline \multirow{2}{*}{$\begin{array}{l}\text { Lâminas } \\
(\% \text { ECA) }\end{array}$} & \multicolumn{5}{|c|}{ Safras } \\
\hline & $00 / 01$ & $01 / 02$ & $02 / 03$ & $03 / 04$ & $04 / 05$ \\
\hline 0 & $582,19 b$ & $505,74 a$ & $514,58 b$ & $502,71 \mathrm{a}$ & $464,92 \mathrm{a}$ \\
\hline 60 & $483,88 \mathrm{ab}$ & $454,80 \mathrm{a}$ & $428,84 \mathrm{a}$ & $547,82 \mathrm{a}$ & $398,64 a$ \\
\hline 80 & $476,60 \mathrm{a}$ & $466,48 a$ & $423,14 \mathrm{a}$ & $502,51 \mathrm{a}$ & $330,49 a$ \\
\hline 100 & $425,27 \mathrm{a}$ & $450,26 a$ & $453,55 \mathrm{ab}$ & $497,76 a$ & $356,36 a$ \\
\hline 120 & $424,98 \mathrm{a}$ & $460,97 a$ & $460,12 \mathrm{ab}$ & $515,85 \mathrm{a}$ & $357,41 \mathrm{a}$ \\
\hline 140 & $412,14 \mathrm{a}$ & $464,79 a$ & $484,66 a b$ & $545,94 a$ & $338,73 \mathrm{a}$ \\
\hline
\end{tabular}

Médias seguidas pela mesma letra, nas colunas, não se diferem estatisticamente entre si pelo teste de Tukey (5\%)

onde a necessidade de maior volume de café da roça do $\mathrm{T} 1$, para compor uma saca a de $60 \mathrm{~kg}$, pode ser explicada em função do grau de maturação no momento da colheita.

O resumo da análise de variância com a soma de quadrados (SQ), para o grau de maturação dos tratamentos no momento da colheita, porcentuais de frutos nos estádios verdes, verde-cana, cereja e passa, para todas as safras e diferentes lâminas aplicadas apresentam-se na Tabela 5 . As médias dos porcentuais de grãos colhidos do cafeeiro, conforme os estádios de maturação para as cinco safras em estudos, constam da Tabela 6.

Pela Tabela 6, observa-se que, na safra 00/01, o tratamento não irrigado (T1) apresentava elevado porcentual de frutos nos estádios cereja $(57,37 \%)$ e passa $(25,66 \%)$ e apenas $16,97 \%$ de frutos nos estádios verde, verde-cana e seco. Para safra $02 / 03$, esses valores foram da ordem de $60,20 \%, 9,26 \%$ e 30,54\%, respectivamente. De acordo com Bartholo \& Guimarães (1997), o teor porcentual de umidade dos grãos nos estádios cereja, passa e verde são 45 a 55\%, 30 a 40\% e 60 a 70\%, respectivamente. No processo de secagem, os grãos perdem muita água e conseqüentemente sofrem redução do seu peso, gastandose assim maior volume de café para se obter uma saca de $60 \mathrm{~kg}$. Assim, é de se esperar que tratamentos que apresentarem elevados porcentuais de frutos nos estádios cereja, passa e verde tenham menor rendimento, ou seja, precisa-se de maior volume de café da roça para se obter uma saca de $60 \mathrm{~kg}$, como o caso do tratamento não irrigado (T1) na primeira safra. Entre todos os tratamentos, exceção feita à safra 03/04, o T1 apresentou piores rendimentos em quatro de cinco safras estudadas.

Ao contrário da primeira e terceira safra, a quinta safra, como observa-se na Tabela 4 , foi a que obteve o melhor rendimento para os tratamentos T2, T3, T4 e T5. Observando-se a Tabela 4, visualiza-se que esses tratamentos, nessa safra, apresentavam elevado porcentual de frutos no estádio seco, acima de $57 \%$, o que culminou com melhores rendimentos. Os tratamentos T1 e T3 para a quinta safra, obtiveram, respectivamente, o pior e melhor rendimento, mesmo que não tenham sido estatísticamente diferenciados, cujos motivos foram anteriormente comentados. O avançado estádio de maturação registrado na quinta safra, para todos os tratamentos, deve-se a problemas operacionais para o início da colheita das parcelas experimentais o que promoveu atrasos, fazendo com que os frutos atingissem o estádio seco.

Os baixos valores porcentuais de frutos nos estádios verde para o tratamento testemunha (T1) devemse ao somatório dos altos valores porcentuais de frutos nos estádios cereja, passa e seco com valor médio de $79,57 \%$ para as cinco safras em estudo, indicando que a maturação é mais precoce na ausência de irrigação, conforme observado por autores como Clemente et al. (2002) e Rezende et al. (2005). Com exceção feita à safra 03/04, o tratamento testemunha, quando comparado aos tratamentos irrigados, apresentou para todas as safras efeito significativo $(\mathrm{P}<0,05)$ quanto ao estádio de maturação cereja, e também os maiores valores atingido porcentuais acima de 57\%. Uma maior uniformidade de florada para as cinco safras nos tratamentos não irrigados (T1) pode ter promovido o pegamento mais uniforme dos frutos, em uma mesma época, acarretando maior uniformidade na maturação e resultando em altos porcentuais de grãos cereja. Entre os tratamentos irrigados, em quatro de cinco safras foram registrados maiores valores porcentuais de grãos cerejas para o tratamento de menor lâmina de reposição (T2), embora esses não diferissem estatisticamente.

É conveniente ressaltar ao final deste estudo que a adoção de uma lâmina para todas as fases fenológicas de uma cultura pode estar equivocada tornando-se importante que experimentos sejam conduzidos para determinar as diferenças de consumo de água em diferentes fases fenológicas. 
Tabela 5 - Resumo da análise de variância com a soma de quadrados (SQ) para o grau de maturação, em porcentagem, do cafeeiro cv. Rubi MG-1192 nas safras 00/01, 01/02, 02/03, 03/04, 04/05 para as lâminas aplicadas em função do porcentual da ECA. UFLA - Lavras, MG.

\begin{tabular}{|c|c|c|c|c|c|c|}
\hline \multirow{3}{*}{ F.V. } & \multirow{3}{*}{ G.L. } & \multicolumn{5}{|c|}{ Soma de Quadrados } \\
\hline & & \multicolumn{5}{|c|}{ Safra 2000/2001 } \\
\hline & & Verde & Verde-Cana & Cereja & Passa & Seco \\
\hline Lâmina & 5 & $1953,3^{\mathrm{ns}}$ & $78,9^{\mathrm{ns}}$ & $3378,7^{*}$ & $937,2^{\mathrm{ns}}$ & $307,7^{*}$ \\
\hline Bloco & 2 & $784,8^{\mathrm{ns}}$ & $165,7^{\mathrm{ns}}$ & $65,5^{\mathrm{ns}}$ & $319,9^{\mathrm{ns}}$ & $1,77^{\mathrm{ns}}$ \\
\hline Erro & 10 & 1373,9 & 258,9 & 231,4 & 1405,8 & 55,9 \\
\hline Total & 17 & 4112,0 & 503,5 & 3675,6 & 2662,9 & 365,3 \\
\hline \multicolumn{2}{|c|}{ C.V. $(\%)$} & 44,00 & 45,69 & 14,96 & 47,39 & 46,74 \\
\hline & & \multicolumn{5}{|c|}{ Safra $2001 / 2002$} \\
\hline Lâmina & 5 & $1681,4^{\mathrm{ns}}$ & $9,3^{\mathrm{ns}}$ & $3634,0^{*}$ & $389,8^{\mathrm{ns}}$ & $306,4^{\mathrm{ns}}$ \\
\hline Bloco & 2 & $2139,0^{*}$ & $10,3^{\mathrm{ns}}$ & $75,9^{\text {ns }}$ & $453,2^{*}$ & $801,9^{*}$ \\
\hline Erro & 10 & 1505,0 & 13,5 & 302,3 & 482,6 & 457,6 \\
\hline Total & 17 & 5325,4 & 33,2 & 4012,2 & 1325,5 & 1565,9 \\
\hline \multicolumn{2}{|c|}{ C.V.(\%) } & 35,87 & 20,19 & 19,12 & 41,44 & 46,60 \\
\hline & & \multicolumn{5}{|c|}{ Safra 2002/2003 } \\
\hline Lâmina & 5 & $1731,2^{\text {ns }}$ & $46,3^{*}$ & $4475,17^{*}$ & $386,4^{\mathrm{ns}}$ & $1283,8^{\mathrm{ns}}$ \\
\hline Bloco & 2 & $463,6^{\mathrm{ns}}$ & $10,4^{\mathrm{ns}}$ & $58,44^{\mathrm{ns}}$ & $1,87^{\mathrm{ns}}$ & $132,7^{\mathrm{ns}}$ \\
\hline Erro & 10 & 1640,8 & 17,8 & 290,9 & 397,9 & 745,4 \\
\hline Total & 17 & 3835,5 & 74,4 & 4824,5 & 786,2 & 2161,8 \\
\hline \multicolumn{2}{|c|}{ C.V. $(\%)$} & 36,47 & 24,99 & 21,35 & 41,92 & 44,89 \\
\hline & & \multicolumn{5}{|c|}{ Safra 2003/2004 } \\
\hline Lâmina & 5 & $449,3^{\mathrm{ns}}$ & $90,7^{\mathrm{ns}}$ & $277,6^{\mathrm{ns}}$ & $407,3^{\mathrm{ns}}$ & $496,0^{*}$ \\
\hline Bloco & 2 & $102,2^{\mathrm{ns}}$ & $30,6^{\mathrm{ns}}$ & $419,9^{\mathrm{ns}}$ & $89,4^{\mathrm{ns}}$ & $64,0^{\mathrm{ns}}$ \\
\hline Erro & 10 & 841,3 & 64,8 & 1228,7 & 336,3 & 173,5 \\
\hline Total & 17 & 1392,8 & 186,1 & 1926,2 & 833,0 & 733,6 \\
\hline \multicolumn{2}{|c|}{ C.V.(\%) } & 51,50 & 30,47 & 21,45 & 40,23 & 53,72 \\
\hline & & \multicolumn{5}{|c|}{ Safra 2004/2005 } \\
\hline Lâmina & 5 & $42,1^{\mathrm{ns}}$ & $38,6^{\mathrm{ns}}$ & $6055,5^{*}$ & $429,7^{\mathrm{ns}}$ & $6746,4^{*}$ \\
\hline Bloco & 2 & $0,4^{\mathrm{ns}}$ & $0,4^{\mathrm{ns}}$ & $397,2^{\mathrm{ns}}$ & $41,1^{\mathrm{ns}}$ & $251,6^{\mathrm{ns}}$ \\
\hline Erro & 10 & 31,8 & 56,7 & 861,7 & 677,0 & 1579,0 \\
\hline Total & 17 & 74,3 & 95,6 & 7314,3 & 1147,9 & 8577,0 \\
\hline \multicolumn{2}{|c|}{ C.V.(\%) } & 85,82 & 108,23 & 38,46 & 72,84 & 20,78 \\
\hline
\end{tabular}

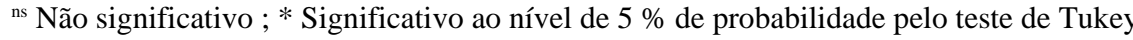


LIMA, L. A. et al.

Tabela 6 - Médias dos porcentuais de grãos colhidos do cafeeiro cv. Rubi MG-1192, conforme o estádio de maturação para as cinco safras estudadas, em função das lâminas de irrigação aplicadas. UFLA - Lavras, MG.

\begin{tabular}{|c|c|c|c|c|c|}
\hline \multirow{3}{*}{ Lâminas } & \multicolumn{5}{|c|}{ Estádios de maturação e seus valores percentuais em cinco safras estudadas } \\
\hline & \multicolumn{5}{|c|}{ Safra 2000/2001 } \\
\hline & Verde & Verde-Cana & Cereja & Passa & Seco \\
\hline 0 & $7,35 \mathrm{a}$ & $8,85 \mathrm{a}$ & $57,37 \mathrm{~d}$ & $25,66 a$ & $0,77 \mathrm{a}$ \\
\hline 60 & $37,60 \mathrm{a}$ & $12,49 \mathrm{a}$ & $39,41 \mathrm{c}$ & $9,58 \mathrm{a}$ & $0,92 \mathrm{a}$ \\
\hline 80 & $19,80 \mathrm{a}$ & $10,81 \mathrm{a}$ & $34,4 \mathrm{bc}$ & $32,08 \mathrm{a}$ & $2,85 \mathrm{ab}$ \\
\hline 100 & $26,85 \mathrm{a}$ & $8,61 \mathrm{a}$ & $24,79 \mathrm{ab}$ & $27,28 \mathrm{a}$ & $12,47 \mathrm{c}$ \\
\hline 120 & $34,39 a$ & $14,71 \mathrm{a}$ & $18,81 \mathrm{a}$ & $26,44 a$ & $5,65 \mathrm{ab}$ \\
\hline \multirow[t]{2}{*}{140} & $33,84 \mathrm{a}$ & $11,35 \mathrm{a}$ & $18,02 \mathrm{a}$ & $29,11 \mathrm{a}$ & $7,68 \mathrm{bc}$ \\
\hline & \multicolumn{5}{|c|}{ Safra 2001/2002 } \\
\hline 0 & $16,60 \mathrm{a}$ & $4,76 \mathrm{a}$ & $60,34 b$ & $11,33 \mathrm{a}$ & $6,97 \mathrm{a}$ \\
\hline 60 & $27,55 \mathrm{a}$ & $5,84 \mathrm{a}$ & $24,06 \mathrm{a}$ & $23,53 a$ & $19,02 \mathrm{a}$ \\
\hline 80 & $41,47 \mathrm{a}$ & $6,25 a$ & $19,36 a$ & $20,18 \mathrm{a}$ & $12,74 \mathrm{a}$ \\
\hline 100 & $33,68 \mathrm{a}$ & $6,54 \mathrm{a}$ & $22,06 a$ & $19,29 \mathrm{a}$ & $18,43 a$ \\
\hline 120 & $43,50 \mathrm{a}$ & $4,83 \mathrm{a}$ & $23,03 a$ & $15,39 \mathrm{a}$ & $13,25 \mathrm{a}$ \\
\hline \multirow[t]{2}{*}{140} & $42,39 a$ & $6,39 a$ & $23,65 a$ & $10,87 \mathrm{a}$ & $16,7 \mathrm{a}$ \\
\hline & \multicolumn{5}{|c|}{ Safra 2002/2003 } \\
\hline 0 & $22,18 \mathrm{a}$ & $3,46 \mathrm{a}$ & $60,20 b$ & $9,26 \mathrm{a}$ & $4,90 \mathrm{a}$ \\
\hline 60 & $31,14 \mathrm{a}$ & $4,30 \mathrm{a}$ & $20,85 a$ & $20,43 a$ & $23,28 \mathrm{a}$ \\
\hline 80 & $30,96 a$ & $4,97 \mathrm{ab}$ & $13,99 a$ & $21,32 \mathrm{a}$ & $28,76 a$ \\
\hline 100 & $30,36 a$ & $8,59 b$ & $18,17 \mathrm{a}$ & $14,74 \mathrm{a}$ & $28,16 a$ \\
\hline 120 & $44,96 a$ & $5,06 \mathrm{ab}$ & $19,14 \mathrm{a}$ & $14,69 \mathrm{a}$ & $16,15 a$ \\
\hline \multirow[t]{2}{*}{140} & $51,15 \mathrm{a}$ & $5,62 \mathrm{ab}$ & $19,20 \mathrm{a}$ & $9,87 \mathrm{a}$ & $14,16 a$ \\
\hline & \multicolumn{5}{|c|}{ Safra 2003/2004 } \\
\hline 0 & $19,64 a$ & $12,76 \mathrm{a}$ & $59,49 \mathrm{a}$ & $6,41 \mathrm{a}$ & $1,70 \mathrm{a}$ \\
\hline 60 & $21,59 a$ & $7,62 \mathrm{a}$ & $49,27 \mathrm{a}$ & $15,35 \mathrm{a}$ & $6,17 \mathrm{ab}$ \\
\hline 80 & $8,34 \mathrm{a}$ & $5,99 a$ & $49,64 a$ & $20,62 \mathrm{a}$ & $15,41 b$ \\
\hline 100 & $18,79 a$ & $7,05 \mathrm{a}$ & $47,44 a$ & $12,32 \mathrm{a}$ & $14,40 \mathrm{~b}$ \\
\hline 120 & $23,57 \mathrm{a}$ & $9,59 \mathrm{a}$ & $50,77 \mathrm{a}$ & $12,46 a$ & $3,61 \mathrm{ab}$ \\
\hline \multirow[t]{2}{*}{140} & $14,93 \mathrm{a}$ & $7,14 \mathrm{a}$ & $53,36 \mathrm{a}$ & $19,33 \mathrm{a}$ & $5,24 a b$ \\
\hline & \multicolumn{5}{|c|}{ Safra 2004/2005 } \\
\hline 0 & $2,29 \mathrm{a}$ & $4,28 \mathrm{a}$ & $64,12 b$ & $8,61 \mathrm{a}$ & $20,70 \mathrm{a}$ \\
\hline 60 & $5,33 \mathrm{a}$ & $4,22 \mathrm{a}$ & $21,46 a$ & $6,83 a$ & $62,14 b$ \\
\hline 80 & $0,86 \mathrm{a}$ & $1,35 \mathrm{a}$ & $9,85 \mathrm{a}$ & $5,82 \mathrm{a}$ & $82,12 b$ \\
\hline 100 & $0,93 \mathrm{a}$ & $0,79 a$ & $13,68 \mathrm{a}$ & $16,11 \mathrm{a}$ & $68,50 \mathrm{~b}$ \\
\hline 120 & $1,59 \mathrm{a}$ & $1,40 \mathrm{a}$ & $14,67 \mathrm{a}$ & $11,17 \mathrm{a}$ & $71,15 b$ \\
\hline 140 & $1,47 \mathrm{a}$ & $1,15 \mathrm{a}$ & $21,04 \mathrm{a}$ & $19,23 \mathrm{a}$ & $57,12 b$ \\
\hline
\end{tabular}

Médias seguidas pela mesma letra, nas colunas, não diferem estatisticamente entre si pelo teste de Tukey (5\%). 


\section{CONCLUSÕES}

A irrigação promoveu acréscimo significativo na produtividade do cafeeiro (Coffea arabica L. cv. Rubi), quando comparada à produtividade do tratamento sem irrigação.

As plantas irrigadas com lâmina de $60 \%$ da ECA apresentaram a maior produtividade média, $45,12 \mathrm{sc} \mathrm{ha}^{-1}$ ano $^{-1}$, para as cinco safras estudadas, com acréscimo de $119 \%$ na produtividade do cafeeiro, quando comparada ao tratamento não irrigado, devendo ser recomendada, por razões técnicas e econômicas para a irrigação, via pivô central na lavoura cafeeira de Lavras, MG.

O grau de maturação no momento da colheita influenciou o rendimento dos tratamentos e, entre os vários estádios de maturação, os grãos cereja e o seco foram os que mais interferiram no rendimento dos tratamentos.

$\mathrm{O}$ tratamento não irrigado (T1) apresentou em quatro de cinco safras pior rendimento; necessitando de uma maior quantidade de litros de café da roça, para formar uma saca de $60 \mathrm{Kg}$.

Recomenda-se ainda que experimentos que avaliem o efeito da irrigação sobre a produtividade e rendimento do cafeeiro devam durar, ao menos, cinco anos.

\section{AGRADECIMENTOS}

Ao Professor Adjunto DEG/UFLA, Luis Artur Alvarenga Vilela (in memoriam) pelo apoio na instalação e condução do experimento durante os primeiros anos.

Ao Conselho Nacional de Pesquisas e Desenvolvimento Tecnológico (CNPq), pela concessão de bolsas de estudos ao segundo e terceiro autor, ex-bolsistas do PIBIq/UFLA, e por fomentar a execução deste experimento junto ao Programa Nacional de Pesquisa e Desenvolvimento da Cafeicultura (PNP\&D/Café).

\section{REFERÊNCIAS BIBLIOGRÁFICAS}

AGRIANUAL. Anuário da agricultura brasileira. 12. ed. São Paulo: FNP Consultoria \& Agroinformativos, 2007.

BARTHOLO, G. F.; GUIMARÃES, P. T. G. Cuidados na colheita e preparo do café. Informe Agropecuário, Belo Horizonte, v. 18, n. 187, p. 33-42, 1997.

BERNARDO, S.; SOARES, A. A.; MANTOVANI, E. C. Manual de irrigação. 8. ed. Viçosa: UFV, 2006. 625 p.

BRASIL. Ministério da Agricultura. Departamento Nacional de Meteorologia. Normas climatológicas 1961-1990. Brasília, DF, 1992. 84 p.
CASTRO NETO, P.; VILELA, E. de A. Veranico: um problema de seca no período chuvoso. Informe Agropecuário, Belo Horizonte, v. 12, n. 138, p. 59-62, 1986.

CLEMENTE, F. M. V. T.; FARIA, M. A. de; GUIMARÃES, R. J. Produtividade, rendimento, maturação e tamanho do grão do cafeeiro (Coffea arabica L. CV Topázio MG-1190), sob diferentes épocas de irrigação. In: SIMPÓSIO BRASILEIRO DE PESQUISA EM CAFEICULTURA IRRIGADA, 5., 2002, Araguari. Anais... Araguari: UFU, 2002. p. 33-36.

COELHO, G. Épocas de irrigação, parcelamentos de adubação e custo de produção do cafeeiro 'Catuaí' na região de Lavras - MG. 2005. 107 p. Tese (Doutorado em Engenharia Agrícola) - Universidade Federal de Lavras, Lavras, 2005.

CONTIN, F. S.; COSTA, M. A.; VICENTE, R. M.; SOARES, A. R.; MANTOVANI, E. C. Produtividade do cafeeiro irrigado por diferentes sistemas de irrigação na região da zona da Mata de Minas Gerais. In: SIMPÓSIO BRASILEIRO DE PESQUISA EM CAFEICULTURA IRRIGADA, 7., 2005, Araguari. Anais... Araguari: UFU, 2005. p. 26-29.

CUSTÓDIO, A. A. de P.; GOMES, N. M.; LIMA, L. A. Efeito da irrigação sobre a classificação do café. Engenharia Agrícola, Jaboticabal, v. 27, n. 3, p. 691-701, set./dez. 2007.

GOMES, N. M.; LIMA, L. A.; CUSTÓDIO, A. A. de P. Crescimento vegetativo e produtividade do cafeeiro irrigado no sul do Estado de Minas Gerais. Revista Brasileira de Engenharia Agrícola e Ambiental, Campina Grande, v. 11, n. 6, p. 564-570, 2007.

MELO, B. de; MARCUZZO, K. V.; TEODORO, R. E. F.; ÁVILA, L. A. de; GONÇALVES, M. V. Desenvolvimento e produtividade de cultivares de cafeeiro submetido à irrigação em diferentes espaçamentos na linha de plantio: safra 2004. In: SIMPÓSIO BRASILEIRO DE PESQUISA EM CAFEICULTURA IRRIGADA, 7., 2005, Araguari. Anais... Araguari: UFU, 2005. p. 54-56.

REZENDE, F. C.; FARIA, M. A. de; OLIVEIRA, S. dos R.; SILVA, M. de L. O. e; ANDRADE, G. P. C.; MATIOLLI, W. Produção e maturação de frutos do cafeeiro (coffea arabica L. TOPÁZIO MG-1190) em função de diferentes lâminas de irrigação. In: SIMPÓSIO BRASILEIRO DE PESQUISA EM CAFEICULTURA IRRIGADA, 7., 2005, Araguari. Anais... Araguari: UFU, 2005. p. 75-79. 
REZENDE, F. C.; OLIVEIRA, S. dos R.; FARIA, M. A. de; ARANTES, K. R. Características produtivas do cafeeiro (Coffea arabica L. cv., Topázio MG-1190), recepado e irrigado por gotejamento. Coffee Science, Lavras, v. 1, n. 2, p. 103-110, jul./dez. 2006.

SANTINATO, R.; FERNANDES, A. L. T.; FERNANDES, D. R. Irrigação na cultura do café. Campinas: Arbore, 1996. $146 \mathrm{p}$.

SILVA, A. M. da; COELHO, G.; FARIA, M. A. de; SILVA, P. A. M.; GUIMARÃES, P. T. G.; COELHO, M. R.; COELHO, G. S. Avaliação do efeito da época de irrigação e da fertirrigação sobre a produtividade e qualidade do café (safra 1999/2000). Engenharia Agrícola, Jaboticabal, v. 22 , n. 3 , p. 312-321, set. 2002 .

SILVA, A. M. da; LIMA, E. P.; COELHO, G.; COELHO, M. R.; COELHO, G. S. Produtividade, rendimento de grãos e comportamento hídrico foliar em função da época, parcelamento e do método de adubação do cafeeiro Catuaí. Engenharia Agrícola, Jaboticabal, v. 23, n. 3, p. 434-440, set./dez. 2003.

SILVA, M. de L. O.; FARIA, M. A. de; MATTIOLI, W.; ANDRADE, G. P. C. Comportamento da produtividade acumulada de seis anos do cafeeiro (Coffea arabica L.) sob diferentes lâminas de irrigação. In: SIMPÓSIO DE PESQUISA DOS CAFÉS DO BRASIL, 4., 2005, Londrina. Anais... Londrina, 2005. CD-ROM. 